\title{
DESAIN SISTEM KONTROL TEMPERATUR UNTUK TIPE PEMANAS DENGAN RESISTANSI RENDAH
}

\author{
Agus B. Jatmika ${ }^{*}$, D.J.Djoko H.S. \\ Program Studi Magister Fisika, Universitas Brawijaya Malang 65145 \\ *E-Mail: abjat68@gmail.com
}

\begin{abstract}
ABSTRAK
Telah didesain sistem kontrol temperatur untuk tipe pemanas dengan resistansi rendah $(10 \mathrm{~m} \Omega)$. Kontrol pemanasan dilakukan dengan menggunakan transfomator untuk menghasilkan tegangan pangkal yang rendah dan arus tinggi, sedangkan algoritma sistem kontrol dikembangkan berdasarkan metode tuning PID Ziegler-Nichols. Faktor koreksi untuk parameter PID dari hasil metode Ziegler-Nichols digunakan untuk mereduksi nilai overshoot akibat laju pemanasan yang lebih cepat. Hasil penelitian menunjukkan bahwa sistem yang dirancang dapat bekerja pada tiap nilai set point temperatur yang diberikan meliputi 150, 160, 170, 180, 190 dan $200{ }^{\circ} \mathrm{C}$ dengan waktu respon sekitar 150 sekon dan rata-rata standar deviasi sekitar $0,61 \%$. Sedangkan hasil pengujian sistem terhadap gangguan menunjukkan bahwa waktu relaksasi yang dibutuhkan sistem untuk menjadi stabil berlangsung sekitar 30 sekon.
\end{abstract}

Kata kunci: Pemanas Resistansi Rendah; Kontrol Temperatur; Transformator; PID ZieglerNichols.

\begin{abstract}
The temperature control system for the low resistance heater $(10 \mathrm{~m} \Omega)$ was designed. The heating control was operated using transformer to produce the low base voltage and high current. In addition, the control system algorithm was developed based on PID Ziegler-Nichols tuning method. The correction factor for PID parameter of the Ziegler-Nichols method results was used to reduce the overshoot value due to the faster heating rates. It showed that the designed system can work properly on any given set point of temperature $\left(150,160,170,180,190\right.$ and $\left.200{ }^{\circ} \mathrm{C}\right)$ under the response time (150 seconds) and the average of standard deviation $(0.61 \%)$. Moreover the interferences test toward the control system showed time relaxation (approx. 30second) of the control system to attain stable condition.
\end{abstract}

Keywords: Heating Low Resistance; Temperature Control; Transformers; PID Ziegler-Nichols.

\section{PENDAHULUAN}

Pemanfaatan komponen pemanas yang bekerja secara resistif dewasa ini semakin berkembang, hal ini terkait dengan kemudahan dalam pengaturan temperatur pemanasan. Faktor penting dalam pemanasan resistansi adalah faktor efisiensi, dimana daya maksimum pemanasan ditentukan oleh minimum resistansi yang harus digunakan. ${ }^{1}$ Selain itu, besarnya arus dari sumber juga berpengaruh secara signifikan terhadap daya yang dihasilkan dan laju pemanasan. ${ }^{2}$ Semakin besar daya pemanasan maka semakin besar pula nilai resistansi pemanas yang dibutuhkan, hal ini berdampak pada besarnya arus sumber yang dibutuhkan untuk komponen pemanas tersebut.

Pemanfaatan pemanas dengan resistansi rendah memiliki beberapa kelebihan diantaranya kebutuhan daya input yang relatif kecil dan laju pemanasan yang lebih cepat, namun tipe pemanas ini membutuhkan tegangan pangkal yang kecil dan gejala overshoot 
yang besar dalam sistem pengaturan.

Dari beberapa penelitian yang telah dilakukan terkait dengan perancangan sistem untuk kontrol pemanas menunjukkan bahwa sebagian besar sistem kontrol yang dirancang menggunakan tipe pemanas dengan resistansi diatas $1 \Omega .^{3-4}$ Untuk tipe pemanas dengan resistansi rendah diperlukan suatu modifikasi dari sistem untuk membatasi tegangan pangkal pemanas agar tidak terjadi kerusakan maupun terjadinya hubungan singkat (short circuit) secara kelistrikan. Sedangkan gejala overshoot yang besar terjadi karenanya respon pemanasan dari elemen lebih cepat sehingga diperlukan nilai koreksi untuk parameterparameter kontrol yang diberikan.

Jurnal ini terkait dengan desain sistem kontrol temperatur untuk tipe pemanas dengan resistansi rendah. Komponen pemanas yang digunakan berupa pemanas tungsten dengan resistansi sekitar $10 \mathrm{~m} \Omega$, komponen tersebut digunakan sebagai pemanas deposan pada evaporator vakum. Pengaturan daya pemanasan menggunakan komponen transformator untuk menghasilkan tegangan pangkal pemanas yang kecil namun arus yang besar, sedangkan sistem kontrol dikembangkan berdasarkan algoritma PID Ziegler-Nichols (ZNM) dengan menambahkan beberapa faktor koreksi untuk mengurangi gejala overshoot yang terjadi.

\section{METODE PENELITIAN}

Skematik dari pengujian sistem sebagaimana ditunjukkan pada Gambar 1, pemanas tungsten diletakkan dalam evaporator vakum untuk menghindari proses oksidasi yang dapat merusak komponen tersebut.Temperatur pemanasan diukur menggunakan sensor termokopel tipe-K dan ditampilkan dalam LCD 16 x 2. Tekanan dalam sistem vakum diatur pada keadaan tunak (sekitar 400 mTorr) dengan cara memindahkan udara dari dalam evaporator vakum menggunakan pompa vakum jenis rotari.

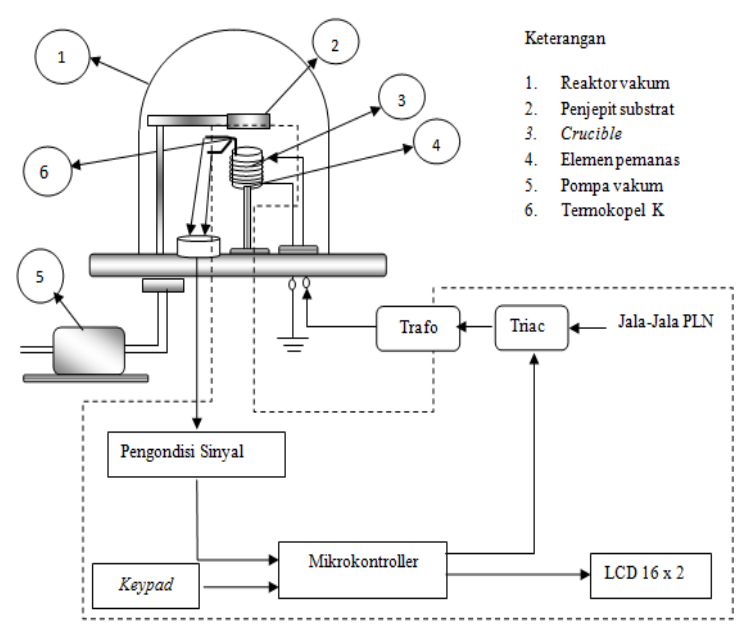

Gambar 1. Skematik pengujian sistem kontrol pemanas pada evaporator vakum.

\section{A. Desain pengaturan daya}

Pengaturan daya untuk elemen pemanas dilakukan dengan memanfaatkan komponen transformator step down (Gambar 2) dengan perbandingan lilitan $220: 1$, kapasitas daya dari transformator sebesar 20 watt dengan perkiraan temperatur maksimum yang mampu dihasilkan sebesar $200{ }^{0} \mathrm{C}$. 
Bagian primer dari trafo terhubung dengan tegangan AC $220 \mathrm{~V}$ dan komponen TRIAC, sedangkan bagian sekundernya terhubung secara langsung dengan pemanas tungsten, sisi sekunder dari trafo memiliki karakteristik berupa tegangan rendah (1V) dan arus keluaran yang relatif besar sekitar $20 \mathrm{~A}$.

Pengaturan daya pemanasan sesuai dengan algoritma PID yang diimplementasikan dalam bentuk sinyal PWM, sinyal ini difungsikan untuk menjalankan komponen TRIAC ketika keadaan zero voltage pada tegangan AC dicapai. Ketika TRIAC diaktifkan, terjadi keadaan konduksi yang menyebabkan arus dapat mengalir pada sisi primer dari trafo dan menimbulkan ggl induksi pada trafo. Besarnya tegangan pada sisi sekunder akibat adanya peristiwa induksi sebanding dengan nilai tegangan pada sisi primernya, semakin lama komponen TRIAC diaktifkan maka tegangan sekunder yang dihasilkan juga semakin besar, jika besarnya arus yang mengalir pada komponen pemanas bergantung pada tegangan pangkal dan resistifitas dari komponen tersebut maka besarnya daya yang terdisipasi dapat ditentukan berdasarkan lamanya waktu aktif dari komponen TRIAC.

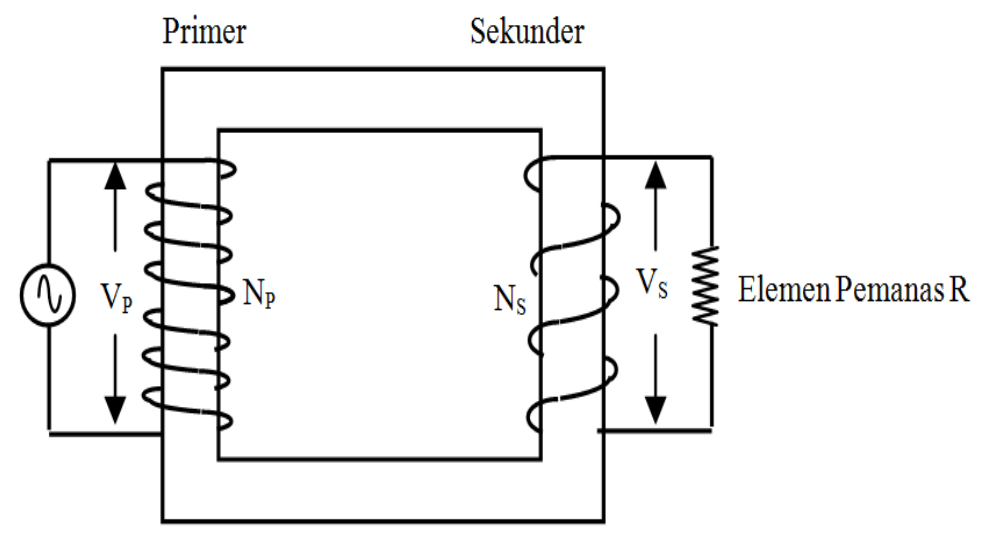

Gambar 2. Kontruksi dari komponen trafo.

Efektifitas proses pengontrolan tegangan AC dapat dicapai ketika pada awal pengontrolan tegangan dalam kondisi zero voltage, hal ini terkait dengan rata-rata daya yang dapat dikontrol. Dengan memanfaatkan rangkaian zero crossing detector maka kondisi zero voltage dari tegangan $\mathrm{AC}$ dapat diketahui, kemudian tegangan keluaran dari rangkaian zero crossing dipakai untuk memicu mikrokontroller agar menghasilkan sinyal PWM bagi komponen TRIAC.

\section{B. Desain sistem kontrol temperatur PID}

Sistem kontrol pemanas resistansi rendah dirancang dengan mekanisme menggunakan sistem kontrol loop tertutup dengan umpan balik sensor termokopel tipe K (Gambar 3), mekanisme pengontrolan temperatur pemanasan dilakukan dengan mengatur banyaknya energi listrik yang dialirkan ke pemanas tungsten berdasarkan teknik PWM (Pulse Width Modulation). Apabila suhu aktual $\left(\mathrm{T}_{\mathrm{A}}\right)$ pemanasan berbeda dengan suhu set point $\left(\mathrm{T}_{\mathrm{S}}\right)$ maka selisih antara $\mathrm{T}_{\mathrm{A}}$ dengan $\mathrm{T}_{\mathrm{S}}$ sebagai nilai error dari sistem kontrol, selanjutnya nilai error tersebut dikonversi kedalam bentuk lebar pulsa PWM. Lebar pulsa PWM ditentukan lewat perhitungan PID dengan metode ZNM berdasarkan nilai error dan parameter-parameter PID seperti $\mathrm{K}_{\mathrm{p}}, \mathrm{K}_{\mathrm{i}}$ dan $\mathrm{K}_{\mathrm{d}}$ yang diberikan. Selanjutnya, sinyal PWM difungsikan untuk mengontrol Plant berupa komponen TRIAC, trafo dan elemen pemanas. 


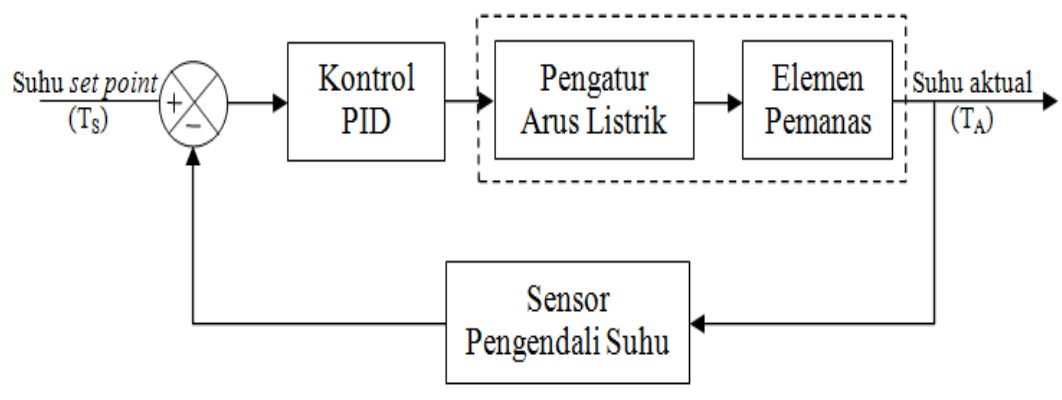

Gambar 3. Diagram blok sistem kontrol pemanas resistansi rendah.

Termokopel tipe-K bekerja berdasarkan koefisien dari Seebeck dengan tegangan keluaran sekitar $41 \mu \mathrm{V}$ per derajat kenaikan temperatur. Disamping itu, sensor termokopel tipe-K juga memerlukan kompensasi titik beku sebagai referensi dari temperatur terendahnya. Oleh karenanya, pada penelitian ini IC MAX 6675 (Maxim Inc.) dimanfatkan sebagai pengolah sinyal termokopel tipe-K, keluaran dari IC tersebut berupa data digital yang dapat langsung dibaca oleh mikrokontroller melalui komunikasi $\mathrm{I}^{2} \mathrm{C} .{ }^{5}$ Kalibrasi pembacaan sensor termokople tipe-K dilakukan dengan membandingkan pembacaan sensor oleh mikrokontroller dengan nilai yang ditampilkan oleh termometer digital HH11B, hasil kalibrasi menunjukkan bahwa selisih pembacaanantara mikrontroler dan termometer sekitar $\pm 0.4^{0} \mathrm{C}$.

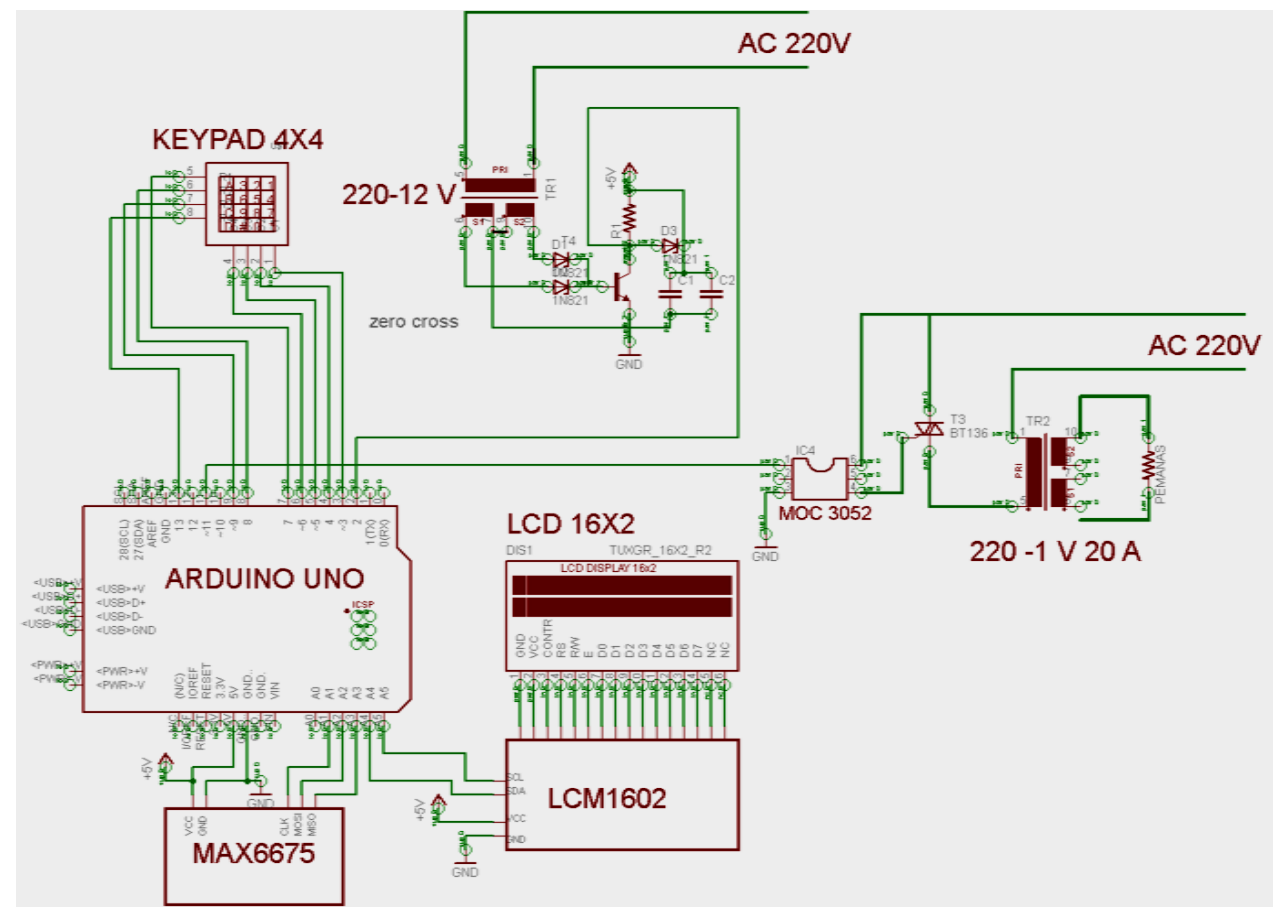

Gambar 4. Skematik rangkaian dari sistem kontrol pemanas

Lebar pulsa PWM ditentukan menurut perhitungan PID ZNM, sesuai dengan persamaan berikut:

$$
D(\%)=T D *\left(K_{p} e+K_{i} \int e d t+K_{d} \frac{d e}{d t}\right)
$$

dimana nilai $D$ merupakan Duty Cycle PWM, TD merupakan faktor skala untuk mengkorversi nilai PID menjadi nilai integer antara 0 hingga 255. Sedangkan konstanta $K_{p}, K_{i}$ dan $K_{d}$ 
merupakan parameter PID yang didapatkan dari proses tunning berdasarkan metode ZieglerNichols (ZNM). Implementasi kontrol PID ke dalam bahasa program mikrokontroller sebagaimana diilustrasikan dalam bentuk flowchart (Gambar 5). Ketika tegangan keluaran dari rangkaian zero crossing bernilai 1 maka program akan mengaktifkan komponen TRIAC melalui pulsa PWM yang dibangkitkan, kondisi ini terjadi untuk tiap siklus dari sinyal AC yang dikontrol baik saat bernilai positif maupun negatif. Program kontrol dapat di atur secara manual maupun automatis. Untuk program manual, program ini digunakan untuk proses tuning PID, sedangkan program automatis dibuat untuk proses pemanasan berdasarkan algoritma PID.

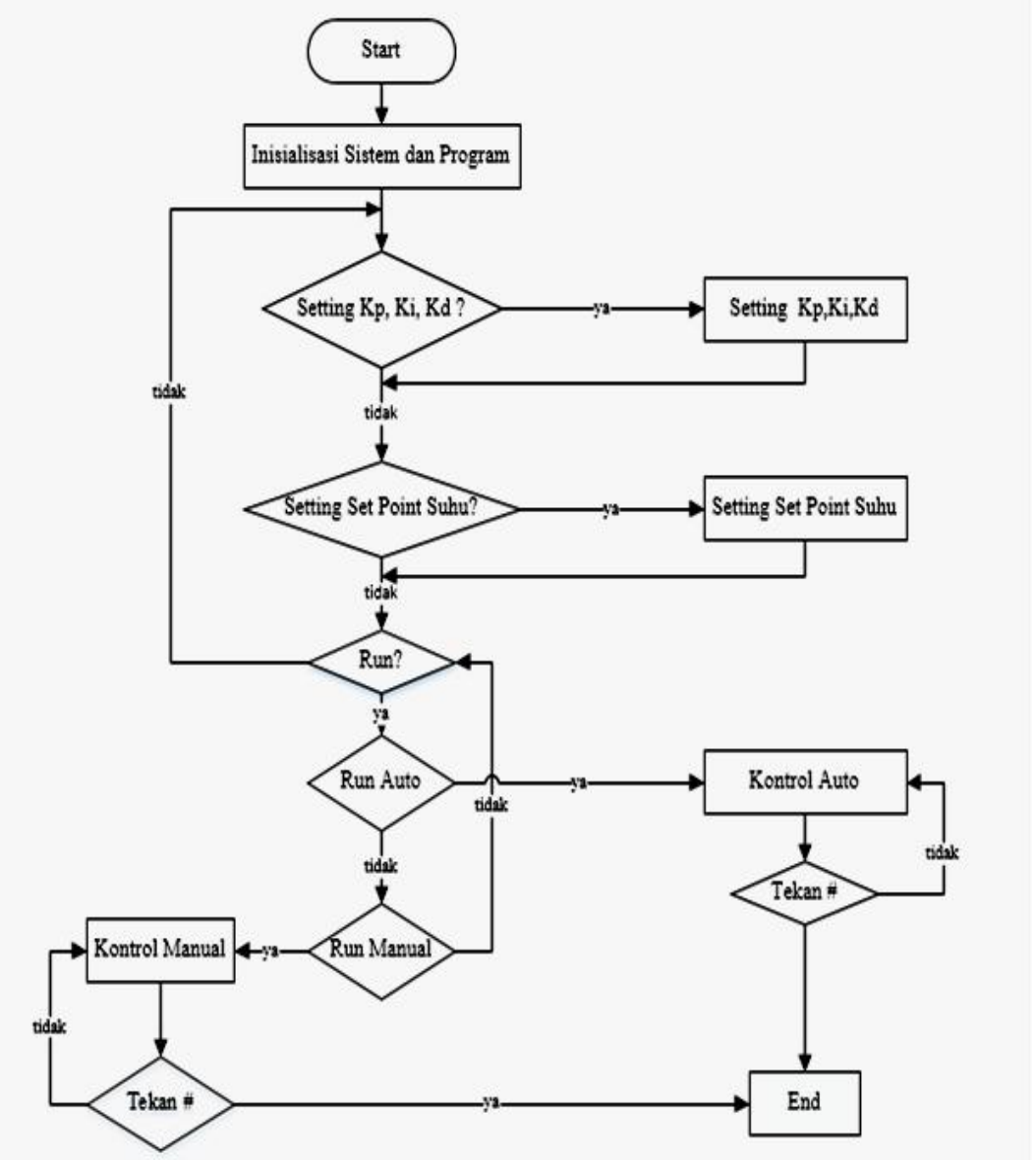

Gambar 5. Flowchart program kontrol pemanas.

Metode tuning PID Ziegler-Nichols diturunkan berdasarkan data eksperimen sehingga diperlukan faktor koreksi terhadap nilai $\mathrm{K}_{\mathrm{p}}, \mathrm{K}_{\mathrm{i}}$ dan $\mathrm{K}_{\mathrm{d}}$ agar didapatkan sistem kontrol yang lebih stabil (6). Faktor koreksi juga dimaksud untuk mengurangi nilai overshoot dari sistem kontrol, hal ini terjadib karena respon pemanasan untuk tipe pemanas resistansi rendah lebih cepat dibandingkan jenis pemanas yang lain. Oleh karenanya, ketika sistem telah mencapai keadaan set point, nilai parameter $\mathrm{K}_{\mathrm{p}}$ dikurangi untuk menghindari kondisi overshoot, besarnya $\mathrm{K}_{\mathrm{p}}$ aktual dapat dituliskan dalam bentuk persamaan menjadi $\mathrm{K}_{\mathrm{p}(\mathrm{aktual})}=\mathrm{K}_{\mathrm{p}(\mathrm{sebelum})}-1$.

\section{Teknik Analisis Data}

Dari pengujian respon alat tanpa umpan balik akan didapatkan grafik respon suhu. Dengan metode Ziegler-Nichols grafik respon suhu terhadap waktu dianalisa untuk mendapatkan nilai parameter $\mathrm{K}_{\mathrm{p}}, \mathrm{K}_{\mathrm{i}}$, dan $\mathrm{K}_{\mathrm{d}}$ yang menjadi dasar perhitungan algoritma PID. 
Dari pengujian respon alat menggunakan algoritma PID yang sudah ditambahkan faktor koreksi parameter $\mathrm{K}_{\mathrm{p}}$ dan $\mathrm{K}_{\mathrm{i}}$ akan didapatkan grafik respon suhu terhadap waktu. Pengujian ini menggunakan SP $150,160,170,180,190$, dan $200^{\circ} \mathrm{C}$. Dari pengujian ini akan diperoleh data respon sistem tiap SP dan data nilai standar deviasi untuk tiap SP.

Dari pengujian respon alat terhadap perubahan gangguan berupa kenaikan tekanan ruang vakum diperoleh data lamanya sistem alat untuk kembali ke keadaan stabil.

\section{HASIL DAN PEMBAHASAN}

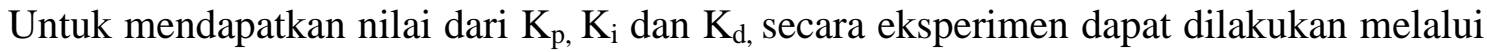
pengujian sistem loop terbuka. Dari hasil pengujian sistem loop terbuka didapatkan grafik respon sistem sebagaimana ditunjukkan pada Gambar 6, dimana parameter $\mathrm{K}_{\mathrm{p}}, \mathrm{K}_{\mathrm{i}}$ dan $\mathrm{K}_{\mathrm{d}}$ dapat diturunkan sesuai dengan metode ZNM.

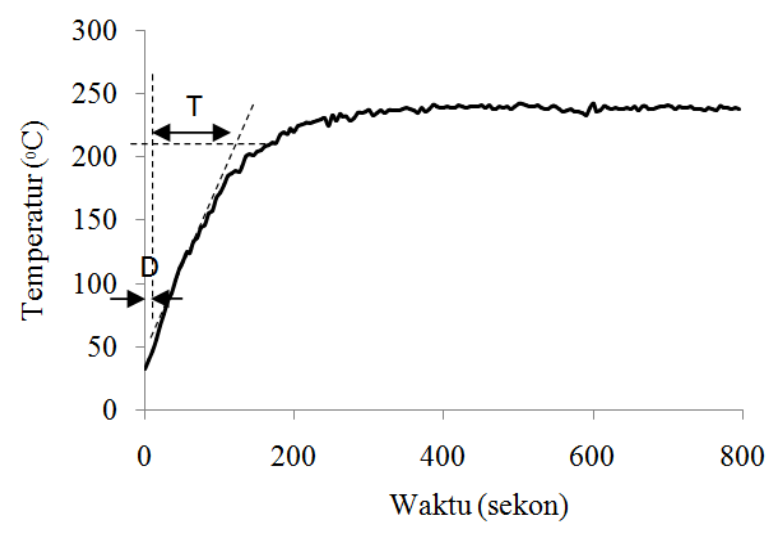

Gambar 6. Respon sistem loop terbuka.

Dari kurva pengujian loop terbuka sebagaimana ditunjukkan Gambar 6, diperoleh nilai $\mathrm{D}=5 \mathrm{~s}$ dan nilai $\mathrm{T}=115 \mathrm{~s}$. Sesuai dengan metode PID ZNM (7), besarnya konstanta $\mathrm{K}_{\mathrm{p}}, \mathrm{K}_{\mathrm{i}}$ dan $\mathrm{K}_{\mathrm{d}}$ dapat ditentukan melalui persamaan berikut:

$$
\begin{aligned}
& K_{p}=\frac{1.2 T}{D} \approx 28 \\
& K_{i}=\frac{K_{p}}{T} \approx 3 \\
& K_{d}=K_{p} * T \approx 69
\end{aligned}
$$

Setelah nilai parameter PID didapatkan maka pengujian selanjutnya adalah pengujian loop tertutup, sistem diuji untuk berbagai nilai SP meliputi temperatur 150, 160, 170, 180, 190 dan $200{ }^{0} \mathrm{C}$. Besarnya nilai SP dipilih berdasarkan kemampuan dari trafo yang dirancang. Sebagaimana terlihat pada Gambar 7, menunjukkan bahwa sistem kontrol yang dirancang mampu bekerja untuk mengatur temperatur pemanasan crucible pada evaporator vakum sesuai dengan nilai SP yang diberikan. Hasil kontrol temperatur menunjukkan bahwa ketika keadaan SP dicapai, sistem akan mengalami osilasi yang relatif kecil dengan nilai standar deviasi rata-rata untuk semua nilai SP sebesar $0.61 \%$. Adanya faktor koreksi untuk nilai $\mathrm{K}_{\mathrm{p}}$ mengakibatkan besarnya overshoot dari sistem dapat direduksi, tetapi efek lain yang muncul bahwa nilai temperatur yang sama dengan nilai SP akan sulit dicapai mengingat adanya faktor pengurangan dari nilai $\mathrm{K}_{\mathrm{p}}$ yang diberikan. Keadaan tunak dari sistem dapat dicapai dalam 
waktu yang relatif singkat sekitar 150 sekon, hal ini terjadi karena adanya faktor respon yang cepat dari komponen pemanas yang digunakan. Pemanas dengan resistansi yang rendah cenderung memiliki respon pemanasan yang lebih cepat jika dibandingkan dengan pemanas dengan tingkat resistansi yang lebih tinggi.

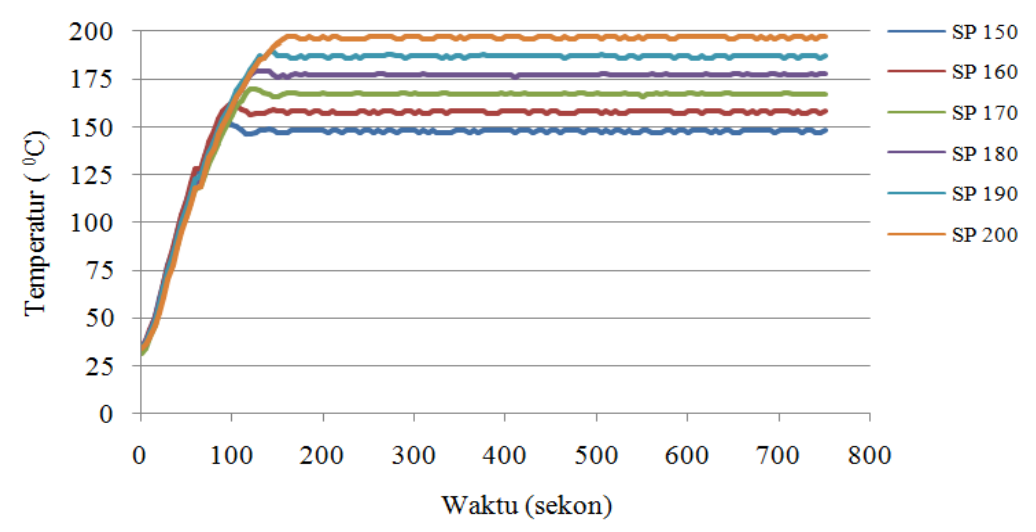

Gambar 7. Grafik respon sistem loop tertutup sebagai fungsi waktu.

Pengujian sistem terhadap gangguan dimaksudkan untuk menguji tingkat kestabilan dari sistem. Faktor gangguan diberikan dengan menaikkan tekanan evaporator, dengan menaikan tekanan evaporator diharapkan temperatur pemanasan akan naik akibat adanya kenaikan densitas dari partikel dalam ruang evaporator vakum. Akan tetapi, berdasarkan data hasil pengujian sistem terhadap gangguan menunjukkan bahwa kenaikan temperatur tidak berlangsung lama dikarenakan respon pemanasan dari sistem bekerja lebih cepat dan adanya faktor koreksi untuk nilai PID yang diberikan (Gambar 8). Sehingga dari hasil pengujian ini dapat dinyatakan bahwa sistem yang dirancang mempunyai tingkat kestabilan yang tinggi dan waktu respon yang lebih cepat.

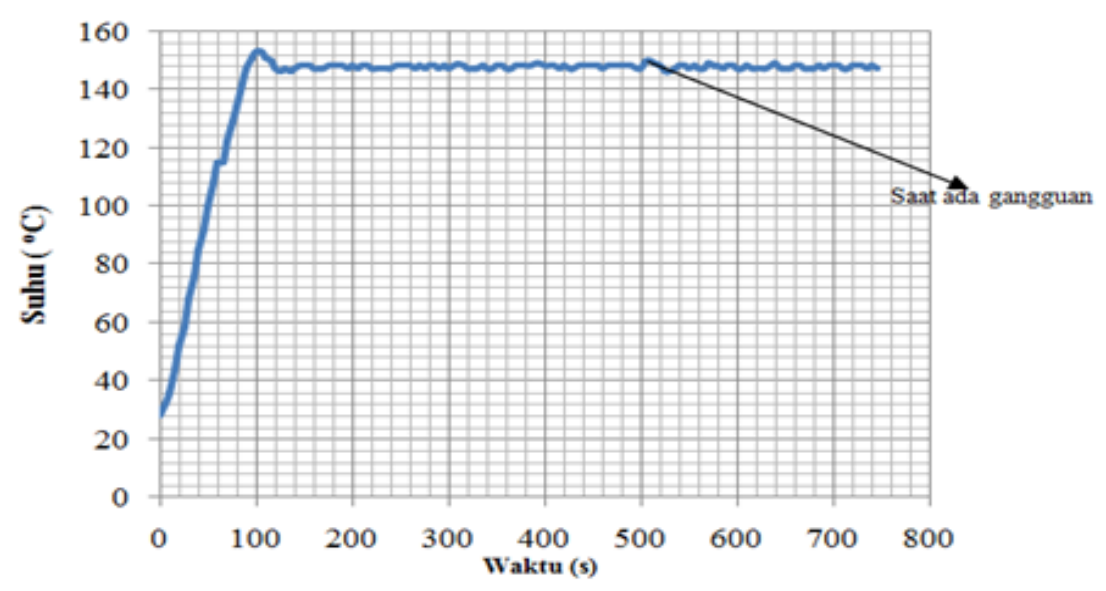

Gambar 8. Grafik respon sistem terhadap gangguan.

Gambar 8 memperlihatkan bahwa ketika pompa vakum dimatikan, dimana terjadi kenaikan tekanan dalam evaporator vakum, temperatur pemanas naik seiring dengan naiknya tekanan (terjadi kenaikan temperatur pemanas sebesar $3^{0} \mathrm{C}$ ), namun setelah terjadi kenaikan temperatur sistem merespon dengan dengan mengubah parameter PID sebagaimana ketika terjadi pada kondisi overshoot, dengan adanya faktor koreksi tersebut maka respon sistem terhadap gangguan menjadi lebih cepat (sekitar 30 sekon). 


\section{KESIMPULAN}

Dari data dan pembahasan sebagaimana yang telah didiskusikan dapat disimpulkan bahwa sistem kontrol temperatur untuk tipe pemanas dengan resistansi rendah yang dirancang mampu bekerja dengan untuk berbagai nilai set point yang diberikan, sistem dapat digunakan sebagai kontrol temperatur dengan mekanisme pengaturan daya menggunakan komponen trafo agar diperoleh tegangan pangkal pemanas yang kecil dan arus pada sisi sekunder yang besar. Untuk mengurangi overshoot akibat respon pemanasan yang cepat dari elemen pemanas digunakan faktor koreksi untuk nilai $\mathrm{K}_{\mathrm{p}}$ dari parameter PID yang didapatkan dengan metode Ziegler-Nichols (MZN). Temperatur maksimum dari sistem yang dirancang dapat ditingkatkan dengan meningkatkan kapasitas daya dari trafo yang digunakan.

\section{UCAPAN TERIMA KASIH}

Penulis mengucapkan terimakasih kepada Yayasan Santa Maria Malang yang sudah memberikan bantuan dana untuk penelitian ini.

\section{DAFTAR PUSTAKA}

1. Karbasian, H., A.E. Tekkaya. A review hot stamping. Journal of Material Processing Tech. 2010;210:2106.

2. Wang, S. et al. Resistance heating using electrically conductive cement. Advancedin Cement Research. 2004;16:161.

3. Rendon, G. et al. A simple substrate heater device with temperature controller for thin film preparation. Journal of Applied Research and Tech. 2012;10:552.

4. Ocaya, R.O., Mbongo, M.. A small-plant PID temperature controller for thermo lumine scence measurement. Pointe-Aux-Piments. 2013;6:883-6

5. Max 6675 datasheet, maxim integrated product Inc., USA. http://www. maximintegrated. com/ MAX6675.pdf

6. Shamsuzzoha, M., Sirgurd Skogestad . The set point overshoot method: a simple and fast closed-loop approach for pid tuning. Journal of Process control. 2010;20:1220-1222.

7. Ogata, K. Teknik kontrol automatik [E. Laksono,trans]. Jilid 1. Jakarta: Erlangga; 1991. 